\title{
Performan Produksi dan Kapasitas Suplay Sapi Bali Bibit dan Potong di Kabupaten Lombok Barat, Nusa Tenggara Barat
}

\section{Production Performance and Supply Capacity of Bali Cattle Breeding and Butting in West Lombok District, West Nusa Tenggara}

\author{
M. Ashari*, Lalu Wirapribadi, Rr.Agustien Suhardiani, \\ Happy Poerwoto, Rina Andriati \\ Program Studi Peternakan, Fakultas Peternakan, Universitas Mataram. \\ *Corresponding Author Email: mohammadashari0498@gmail.com
}

Manuscript received: 08-12-2020. Accepted: 25-10-2021

\begin{abstract}
ABSTRAK
Penelitian ini dilakukan di Kabupaten Lombok Barat dengan tujuan untuk mengetahui performan produksi dan kapasitas suplay sapi Bali bibit dan potong di kabupaten Lombok Barat. Penelitian dilakukan dengan metode survey. Sampel penelitian terdiri dari peternak dan ternak yang dipeliharanya. Penelitian ini dilakukan pada dua kecamatan dan setiap kecamatan dipilih tiga desa sampel. Jumlah sampel sebanyak 60 responden peternak. Variabel yang diamati meliputi bobot badan, ukuran tubuh, angka kelahiran, angka kematian, panen pedet, jangka beranak dan umur afkir. Data yang terkumpul dianalisis secara diskriptif. Untuk mengetahui tingkat produksi dan kapasitas suplay sapi Bali bibit dan potong data dianalisis menggunakan pedoman Dania. Strukur Populasi sapi Bali terdiri atas 33.33\% anak, 21.21\% muda dan 45.45\% dewasa dengan Angka panen anak 26.97\% dan angka kematian 2.49\% dari populasi. Rataan bobot badan sapi Bali di Kabupaten Lombok Barat, anak lepas sapih, muda dan dewasa berturut turut $129.65,247.98$ dan $275.75 \mathrm{~kg}$ dewasa dengan ukuran tinggi gumba, anak lepas sapih 99.08, muda 112.75 dan dewasa $118.45 \mathrm{~cm}$. Kapasitas suplay sapi bibit dan sapi potong Kabupaten Lombok Barat sebesar 24.28\% dari populasi, yang berupa $6.51 \%$ sapi potong dan $17.76 \%$ sapi bibit..
\end{abstract}

Kata kunci: sapi bali; populasi; produksi; ternak bibit; ternak potong.

\footnotetext{
ABSTRACT

This research was conducted in West Lombok Regency with the aim of knowing the production performance and supply capacity of Bali cattle seeds and beef in West Lombok district. The research was conducted by survey method. The research sample consisted of farmers and the livestock they kept. This research was conducted in two sub-districts and three sample villages were selected for each sub-district. The number of samples is 60 farmer respondents. The variables observed included
} 
body weight, body size, birth rate, mortality rate, calf harvest, calving period and age of rejection. The data collected were analyzed descriptively. To determine the level of production and supply capacity of Bali cattle, seeds and cuts, the data were analyzed using Dania guidelines. Structure The population of Bali cattle consists of $33.33 \%$ calves, $21.21 \%$ young and $45.45 \%$ adults with a child harvest rate of $26.97 \%$ and a mortality rate of $2.49 \%$ of the population. The average body weight of Bali cattle in West Lombok Regency, weaning calf, young and adult, respectively, is $129.65,247.98$ and $275.75 \mathrm{~kg}$ adults with gumba height, 99.08 weaning calves, 112.75 young and adults $118.45 \mathrm{~cm}$. The supply capacity of breeder cattle and beef cattle in West Lombok Regency is $24.28 \%$ of the population, consisting of $6.51 \%$ beef cattle and $17.76 \%$ breed cattle.

Keywords: bali cattle; population; production; breeding livestock; beef cattle.

\section{PENDAHULUAN}

Daerah Kabupaten Lombok Barat merupakan salah satu Kabupaten di Nusa Tenggara Barat (NTB) yang berperan aktif sebagai pemasok sapi Bali bibit dan potong untuk berbagai daerah lainnya di Indonesia, terintegrasi dengan peran daerah NTB sebagai salah satu daerah kantong produksi ternak potong nasional. Sapi Bali di Kabupaten Lombok Barat merupakan salah satu aset ekonomi yang cukup penting bagi peningkatan pendapatan masyarakat pedesaan maupun daerah, namun belum banyak mendapat perhatian terutama berkaitan dengan arah pengembangannya.

Pengembangan usaha sapi Bali dipedesaan (peternak kecil) perlu diupayakan guna dapat meningkatkan pendapatan dan kesejahteraan masyarakat, yang berarti pula dapat mempertahankan predikat NTB sebagai wilayah sumber sapi Bali bibit dan potong (gudang ternak). Hal ini berarti dapat menaikan pendapatan asli daerah (PAD), yang sangat penting dalam menunjang pelaksaanaan Otonomi Daerah. Guna mendukung upaya pengembangan dimaksud, dipandang perlu tersedianya data kapasitas suplay sapi bibit dan potong di wilayah Kabupaten Lombok Barat.

Kapasitas suplai sapi Bali bibit sangat dipengaruhi oleh berbagai faktor yang satu sama lainnya saling berkaitan, antara lain: jumlah populasi, struktur populasi, tingkat produktivitas ternak, motivasi pemeliharaan ternak, permintaan pasar dan kebijakan pemerintah serta manajemen beternak yang diterapkan (Muladno, 2012). Jumlah populasi ditentukan oleh pertambahan alami ternak, tingkat kematian, laju pengeluran/pemotongan dan pemasukan ternak (Hardjosoebroto, 1994). Dinamika populasi dengan perencanaan yang terarah dapat mempertahankan stuktur populasi yang seimbang antara anak, muda dan dewasa baik jantan maupun betina. Jumlah sapi Bali muda yang dipertahankan harus mampu memenuhi kebuhan calon betina dan jantan pengganti.

Peningkatan produktivitas ternak dapat ditempuh melalui perbaikan breeding, feeding, dan managemen, yang capaiannya dapat diukur dari penampilan reproduksi dan produksinya. Penampilan reproduksi ditentukan oleh tingkat kelahiran, umur melahirkan pertama, jangka beranak, siklus birahi, post-partum estrus, fertilitas dan lama penggunaan dalam pembiakan (Pane, 1993). Penampilan produksi dapat diukur berdasarkan bobot lahir, angka kematian, panen pedet, umur pubertas, bobot potong dan persentase karkas. Berdasarkan penampilan reproduksi dan produksi tersebut dapat dianalisis besarnya kapasitas suplai sapi Bali bibit dan potong didaerah tersebut. 
Besarnya kapasitas suplai sapi Bali (bibit dan potong), bobot potong dan persentase karkas, menentukan besarnya potensi suplai daging daerah tersebut. Seberapa besar efisiensi usaha dan nilai ekonomis usaha beternak sapi Bali sangat menentukan tingkat keuntungan peternak dan prospek pengembangan usaha beternak sapi Bali, hal ini belum banyak diketahui.

Upaya peningkatan produktivitas dan populasi sapi Bali mutlak perlu dilakukan yang diimbangi dengan kebijakan yang terarah dalam pengendalian pengeluaran dan pemotongan setiap tahun. Untuk dapat melakukan peningkatan tersebut, diperlukan informasi mengenai potensi produksi dan reproduksi sapi Bali serta faktor-faktor yang mempengaruhinya perlu diinvestigasi secara seksama. Untuk mengetahui kemampuan daerah dalam mensuplai sapi bibit dan sapi potong perlu dilakukan pengamatan terhadap variabel-variabel penentu kapasitas suplai tersebut. Hasil penelitian ini diharapkan dapat digunakan sebagai dasar dalam membuat kebijakan dan pengembangan/usaha sapi Bali guna mendukung peningkatan pendapatan dan kesejahteraan masyarakat maupun peningkatan pendapatan daerah.

\section{Waktu dan Tempat Penelitian}

\section{METODE}

Penelitian dilaksanakan selama 6 (enam) bulan mulai bulan April sampai dengan Oktober 2020. Lokasi penelitian dipilih dari wilayah di Kabupaten Lombok Barat yang termasuk wilayah sentra pengembangan sapi Bali di Nusa Tenggara Barat.

Penelitan dilakukan pada 2(dua) kecamatan, yang penentuannya didasarkan pada ketinggian tempat dari permukaan laut, dari setiap kecamatan terpilih ditentukan 3 (tiga) desa sampel. Pengambilan desa sampel berdasarkan tingkat populasi ternak sapi Bali, yakni desa dengan populasi tinggi, sedang dan kurang.

\section{Penentuan Sampel}

Sebagai sampel penelitian adalah peternak dan ternak sapi Bali, Penentuan sampel responden secara purposive sampling. Jumlah responden sebanyak 60 responden peternak (10 peternak di setiap desa sampel). Jumlah ternak yang diamati sesuai dengan jumlah ternak yang dimiliki oleh responden. Keriteria peternak responden adalah telah berpengalaman memelihara sapi minimal 5 (lima) tahun.

\section{Pengumpulan Data}

Jenis data yang diperlukan dari penelitian ini adalah data primer dan data sekunder. Data primer diperoleh melalui pengamatan/pengukuran langsung terhadap ternak dan wawancara terfokus (focused interview) dengan peternak. Data sekunder berupa dokumen resmi diperoleh dari Dinas/Instansi yang terkait dan Biro Pusat Statistik (BPS) di tingkat provinsi, kabupaten serta kecamatan. Selain itu, data sekunder didapat dari hasil penelaahan kepustakaan dan laporan-laporan tertulis lainnya.

\section{Alat Penelitian}

Untuk mendapatkan data menegenai struktur populasidan kinerja reproduksi ternak digunakan alat berupa: 1) daftar pertanyaan (quisioner) yang berisikan semua varibel yang 
dibutuhkan dalam penelitian ini, 2) tongkat dan pita ukur untuk mengukur bagian tubuh ternak.

\section{Variabel yang Diamati}

Variabel yang diamati dalam penelitian ini meliputi: Bobot badan, ukuran tubuh, struktur populasi, servis per conception (S/C), angka kelahiran, panen pedet, angka kematian, selang beranak, umur afkir, umur produktif, lama digunakan dalam pembiakan, dan Natural Increase.

\section{Analisa Data}

Data yang terkumpul ditabulasi menurut jenisnya dan dianalisis secara diskriptif menggunakan rataan, simpangan baku dan persentasenya.Tingkat produktivitas dan kapasitas suplai sapi bibit dan potong di Kabupaten Lombok Barat dianalisis menggunakan pedoman Dania (2013). [4]

\section{Strutur Populasi Sapi Bali}

\section{HASIL DAN PEMBAHASAN}

Struktur populasi ternak ditentukan oleh proporsi dari masing-masing penyusun populasi ternak. Unsur-unsur penyusun populasi ternak terdiri atas jenis kelamin (jantan dan betina), umur fisiologis (anak, muda dan dewasa). Struktur populasi ternak mempengaruhi tingkat perkembangan dari populasi ternak tersebut, karena itu sangat penting untuk mengatur struktur populasi ternak agar terjamin kelestarian populasi ternak. Struktur populasi dipengaruhi oleh teknis breeding yang diterapkan, jumlah keturunan yang dihasilkan tiap beitna dewasa yang ada (Tarumingkeng, 1995). Struktur Populasi sapi Bali di Kabupaten Lombok Barat disajikan pada Tabel 1

Struktur populasi sapi Bali di lokasi penelitian cukup ideal yakni terdiri 33.33\% anak dengan perbandingan jantan dan betina 0.48:0.52 sedangkan sapi Bali muda memperlihatkan proposi yang paling rendah yakni $21.22 \%$. Rendah jumlah sapi Bali muda dari hasil penelitian ini memperlihatkan bahwa usaha yang dijalankan oleh para peternak sapi Bali adalah usaha perbibitan dimana produk yang dijual adalah ternak-ternak bibit baik berupa calon induk pengganti (replacement) maupun ternak bakalan untuk digemukkan.

Tabel 1. Sebaran Populasi Ternak Sapi Bali Menurut umur di Kabupaten Lombok Barat.

\begin{tabular}{ccccccc}
\hline \multirow{2}{*}{ Umur Fisiologis } & Jantan & Betina & Jumlah \\
& $($ ekor $)$ & $(\%)$ & $($ ekor) & $(\%)$ & $($ ekor) & $(\%)$ \\
\hline Anak sapihan & 32 & 16.17 & 34 & 17.17 & 66 & 33.33 \\
Muda & 13 & 6.57 & 29 & 14.65 & 42 & 21.22 \\
Dewasa & 11 & 5.56 & 79 & 39.90 & 90 & 45.45 \\
Total & 56 & 28.28 & 142 & 71.72 & 198 & \\
\hline
\end{tabular}

Struktur populasi sapi Bali dilokasi penelitian kelihatannya cukup baik yakni didominasi oleh ternak dewasa sebanyak $45.45 \%$ dengan perbandingan jantan dan betina yakni 1 ekor jantan berbanding 7 ekor betina. Perbandingan ini termasuk cukup rendah kalau dilihat dari 
kemampuan seekor pantan melayani betina yakni 1 : 20. Hal ini tidaklah mengherankan, karena di lombok barat perkawinan ternak umumnya dilakukan dengan kawin buatan (IB). Pemeliharaan sapi jantan dilakukan untuk tujuan penggemukan kemudian dijual bila sudah mendapat keuntungan.Untuk lebih jelasnya struktur populasi sapi Bali dilokasi penelitian dapat disimak pada Gambar 1.

Bila ditelaah secara teliti struktur populasi sapi Bali dilokasi penelitan tanpak bahwa proporsi betina dewasa yang paling tinggi yakni 39.39\% dan yang paling rendah proporsinya adalah sapi Bali jantan dewasa yakni 5.67\%. Hal ini disebabkan karena sapi betina dewasa merupakan modal utama dalam usaha perbibitan, tingkat produktivitas usaha perbibitan sangat tergantung pada jumlah betina yang dipelihara, renahnya proporsi sapi jantan disebabkan, sebagian besar usaha yang dijalankan peternak adalah usaha perbibitan dengan menggunakan system perkawinan buatan (IB), sehingga kurang membutuhkan ternak jantan untuk pemaceknya.

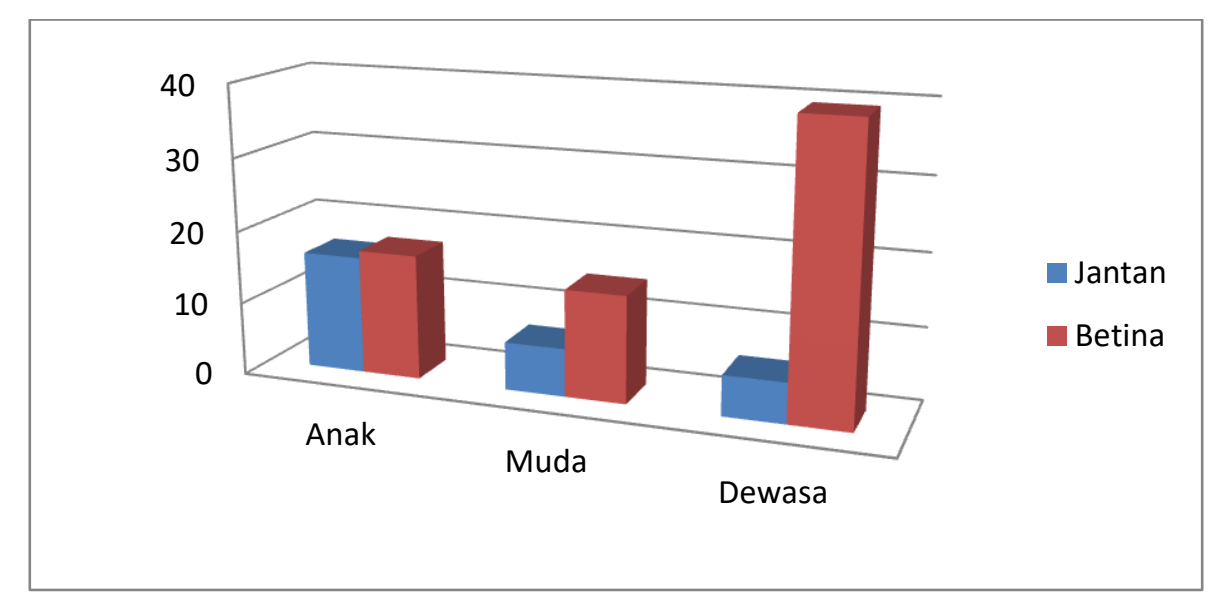

Gambar 1. Struktur populasi (\%) sapi bali di lokasi penelitian

\section{Performan Produksi}

1. Bobot badan

Hasil pengamatan performan produksi sapi Bali di kabupaten Lombok Barat berupa capaian bobot badan pada umur fiologis tertentu.Data dikelompokkan berdasarkan umur dan jenis kelamin ternak. Rata- rata performan produksi sapi Bali meliputi bobot anak sapihan, bobot muda dan bobot dewasa dapat dilihat pada Tabel 2

Penyapihan pada sapi umumnya dilakukan pada umur $6-7$ bulan, karena pada umur tersebut ternak secara fisiologis sudah mampu hidup tanpa tergantung pada induknya. Rataan bobot badan sapi Bali jantan dan betina hasil rekaman pada penelitian ini memperlihatkan bahwa bobot badan sapi Bali jantan 4.28\% lebih tinggi dibandingkan dengan sapi Bali betina pada umur fisiologi lepas sapih. Hal ini disebabkan karena perbedaan kemampuan tumbuh antara ternak jantan dan betina. 
Tabel 2. Rataan bobot badan (kg) sapi Bali pada umur fisiologis anak, muda dan dewasa di Kabupaten Lombok Barat

\begin{tabular}{lccc}
\hline \multirow{2}{*}{ Umur Fisiologis } & \multicolumn{2}{c}{ Jenis Kelamin } & \multirow{2}{*}{ Rataan } \\
\hline Anak Lepas Sapih & $135.20 \pm 17.76$ & $124.10 \pm 26.76$ & $129.65 \pm 16.90$ \\
Muda & $265.00 \pm 12.13$ & $230.95 \pm 31.75$ & $247.98 \pm 14.28$ \\
Dewasa & $328.33 \pm 16.63$ & $244.13 \pm 23.24$ & $275.75 \pm 17.57$ \\
\hline
\end{tabular}

Sapi Bali jantan lepas sapih mencapai bobot badan rata-rata $135.20 \pm 17.76 \mathrm{~kg}$ sedangkan sapi Bali betina bobot badan pada umur yang sama hanya mencapai $124.10 \pm 26.76 \mathrm{~kg}$ dengan rataan tanpa membedakan jenis kelamin yakni $129.65 \pm 16.90 \mathrm{~kg}$. Hasil penelitian ini tidak jauh berbeda dengan hasil penelitian Dwipa, et al. (1989) yang melaporkan, bahwa ratarata bobot Bali umur Lepas sapih $130.3 \pm 8.9 \mathrm{~kg}$. Hal ini mengindikasikan bahwa tingkat manajemen pengelolaan ternak yang diterapkan peternak pada penelitian sebelumnya besar kemungkinan sama dengan penelitian ini sehingga kapasitas produksi yang dicapai ternak sama.

Hasil penelitian terhadap bobot umur muda (1-2 tahun) memperlihatkan kecendrungan yang sama dengan hasil penelitian terhadap parameter bobot umur lepas sapih yaitu sapi jantan memiliki bobot yang lebih tinggi dibanding dengan sapi betina. Rata - rata bobot badan sapi Bali muda di kabupaten Lombok barat yakni $247.98 \pm 14.28 \mathrm{~kg}$ (jantan $265.00 \pm$ $12.13 \mathrm{~kg}$ dan betina $230.95 \pm 31.75 \mathrm{~kg}$ ), bila dianalisis lebih lanjut ternyata sapi Bali Jantan Muda memiliki bobot badan $6.86 \%$ lebih tinggi dari pada sapi Bali betina. Hal ini membuktikan bahwa kinerja produksi ternak sangat ditentukan oleh potensi genetik yang dimiliki oleh ternak, dalam hal ini jenis kelamin mempengaruhi perfoman produksi ternak.

Bobot badan dewasa, bobot badan dewasa ini dicerminkan dari bobot badan umur $\geq 2$ tahun. Rataan bobot badan umur $\geq 2$ tahun pada sapi Bali jantan dan sapi Bali Betina dapat dilihat pada Tabel 4. Hasil penelitian ini memperlihatkan bahwa pencapaian bobot badan dewasa pada sapi Bali jantan lebih tinggi dibanding sapi Bali betina. Bobot badan umur $>2$ tahun pada sapi Bali berkisar $275.75 \pm 17.57 \mathrm{~kg}$ dengan rataan $328.33 \pm 16.63 \mathrm{~kg}$ pada sapi Bali Jantan dan $244.13 \pm 23.24 \mathrm{~kg}$ pada sapi Bali Betina. Hasil yang diperoleh pada penelitianini lebih rendah dari hasil peneltian Arman et al (2007) yang melaporkan bahwa rataan bobot badan sapi Bali jantan mencapai $278.26 \pm 74.91 \mathrm{~kg}$, untuk lebih jelasnya capaian bobot badan pada umur tertentu dapat dilihat pada Gambar 2 


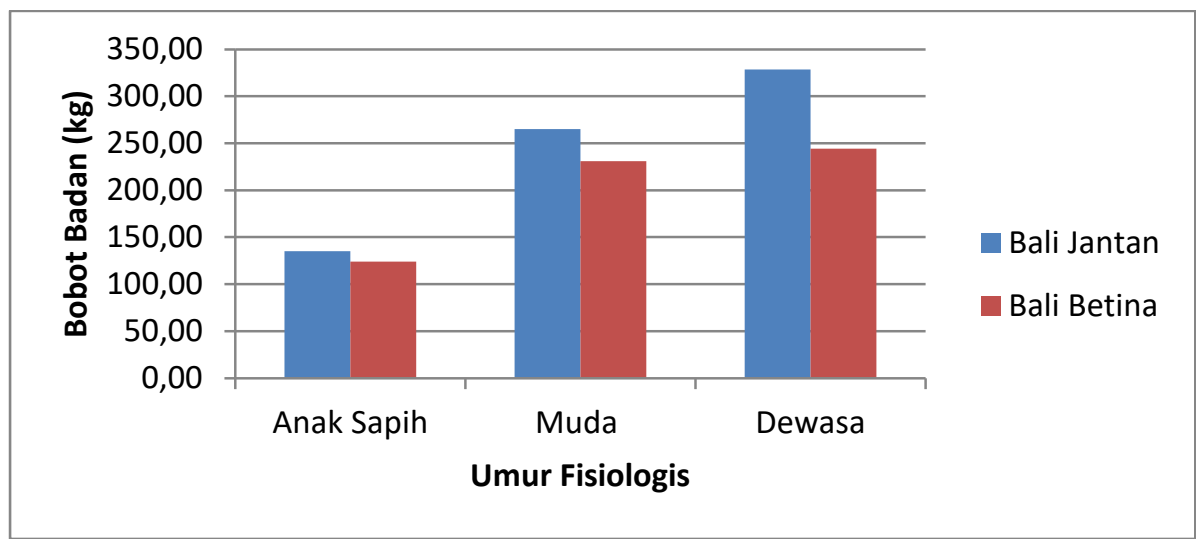

Gambar 2. Diagram bobot badan sapi bali jantan dan sapi bali betina pada umur-umur tertentu.

Hasil analisis statistik menunjukkan bahwa sapi Bali janan dewasa mecapai bobot yang lebih tinggi $14.71 \%$ dibanding dengan bobot badan sapi Bali betina. Hal ini disebabkan adanya perbedaan kecepatan pertumbuhan antara ternak jantan dan ternak betina sebagai akibat dari perbedaan hormon yang dimiliki oleh ternak pada jenis kelamin yang berbeda.

\section{Ukuran Tubuh}

Ukuran tubuh ternak merupakan salah satu kriteria yang digunakan dalam menilai kinerja produksi ternak khususnya dalam usaha pembibitan (breeding).Tinggi gumba, panjang badan dan lingkar dada merupakan ukuran tubuh ternak yang sering digunakan sebagai variabel penentu dalam menilai capaian produksi ternak, disamping itu ukuran tubuh dapat digunakan sebagai patokan dalam menetukan kualitas ternak bibit. Ukuran tubuh mempunyai korelasi dengan bobot badan, ternak bibit dan bakalan dengan ukuran tubuh yang lebih tinggi mempunyai peluang yang lebih besar untuk mencapai bobot dewasa atau bobot potong yang lebih tinggi. Hasil pengamatan ukuran-ukran tubuh sapi Bali di kabupaten lombok barat disajian pada Tabel 3.

Tabel 3. Rataan Panjang Badan, Tinggi Gumba dan Lingkar Dada (cm) Sapi Bali Calon Bibit di Kabupaten LombokBarat

\begin{tabular}{lcccc}
\hline $\begin{array}{l}\text { Umur } \\
\text { fisiologis }\end{array}$ & Kelamin & Tinggi Gumba & $\begin{array}{c}\text { Ukura Tubuh } \\
\text { Panjang Badan }\end{array}$ & Lingkar dada \\
\hline \multirow{3}{*}{ Anak } & Jantan & $90.00 \pm 5.53$ & $76.00 \pm 9.61$ & $114.00 \pm 11.76$ \\
& Betina & $100.22 \pm 4.97$ & $96.05 \pm 10.35$ & $126.65 \pm 9.48$ \\
& Rataan & $99.08 \pm 2.93$ & $93.55 \pm 7.31$ & $123 ., 48 \pm 6.22$ \\
Muda & Jantan & $119.50 \pm 7.53$ & $117.53 \pm 8.30$ & $165.65 \pm 12.51$ \\
& Betina & $106.00 \pm 2.67$ & $118.40 \pm 3.03$ & $154.00 \pm 7.12$ \\
& Rataan & $112.75 \pm 4.00$ & $117.97 \pm 4.48$ & $159.83 \pm 7.35$ \\
Dewasa & Jantan & $121.50 \pm 9.19$ & $125.00 \pm 8.49$ & $179.50 \pm 2.12$ \\
& Betina & $115.00 \pm 2.58$ & $119.85 \pm 5.12$ & $157.30 \pm 4.22$ \\
& Rataan & $118.45 \pm 3.53$ & $120.95 \pm 4.47$ & $159.60 \pm 5.99$ \\
\hline
\end{tabular}

Hasil Penelitian Tinggi gumba sapi Bali calon bibit berkisar antara $101.00-133.00 \mathrm{~cm}$ dengan rataan $112.75 \pm 4.00 \mathrm{~cm}$. Hasil rekaman ini kelihatannya rentang nomerik cukup 
besar, hal ini disebabkan data tinggi gumba yang ditampilan merupakan gabungan ukuran tinggi gumba sapi Bali calon bibit jantan dan betina. Kisaran tinggi gumba sapi Bali calon bibit jantan (bakalan) 107.00 - $133.00 \mathrm{~cm}$ dengan rataan $119.50 \pm 7.53 \mathrm{~cm}$, sedangkan untuk calon bibit betina berkisar antara $101-110 \mathrm{~cm}$ dengan rataan $106.00 \pm 2.67 \mathrm{~cm}$. Hasil penelitian ini sedikit lebih tinggi dibanding hasil penelitian Dwipa, et al. (1989) yang melaporkan Rataan tinggi gumba sapi Bali calon bibit jantan $111.72 \pm 5.43 \mathrm{~cm}$ dan betina $104.65 \pm 4.60 \mathrm{~cm}$.

Hasil penelitian ini memperlihatkan capaian ukuran tubuh sapi Bali bibit yang meliputi ; tinggi gumba, panjang badan dan lingkar dada berada pada kisaran standar bibit sapi Bali yang ditetapkan BSNI (badan standar nasional Indonesia) (Anonim, 2017), mengelompokkan grade/kelas sapi Bali bibit menjadi tiga klas ( I, II, dan III) berdasarkan ukuran tinggi gumba, panjang badan dan lingkar dada.

Tinggi gumba sapi Bali bibit jantan kelas I BSNI menetapkan persyaratan minimum, $115 \mathrm{~cm}$, kelas II 110 dan kelas III $105 \mathrm{~cm}$ sedangkan bibit betina ditetapkan untuk kelas I 107 $\mathrm{cm}$, kelas II $104 \mathrm{~cm}$ dan kelas III $100 \mathrm{~cm}$. berdasarkan persyaratan ketentuan tersebut maka klas bibit sapi Bali jantan di Kabupaten Lombok Barat hasil penelitian ini adalah $60 \%$ kelas I dan $40 \%$ kelas II sedangkan, bibit betina proporsinya $60 \%$ kelas I, $30 \%$ kelas II dan $10 \%$ kelas III.

Panjang badan sapi Bali bibit jantan kelas I BSNI Menetapkan persyaratan minimum, $125 \mathrm{~cm}$, kelas II 120 dan kelas III $115 \mathrm{~cm}$ sedangkan bibit betina ditetapkan untuk kelas I 112 $\mathrm{cm}$, kelas II $105 \mathrm{~cm}$ dan kelas III $101 \mathrm{~cm}$. berdasarkan persyaratan ketentuan tersebut maka klas bibit sapi Bali jantan di Kabupaten Lombok Barat hasil penelitian ini adalah $40 \%$ kelas I, kelas II 30\% dan 30\% kelas III sedangkan sapi bibit betina 100\% kelas I.

Lingkar dada sapi Bali bibit jantan kelas I BSNI Menetapkan persyaratan minimum 155 $\mathrm{cm}$, kelas II 147 dan kelas III $142 \mathrm{~cm}$ sedangkan bibit betina ditetapkan untuk kelas I $139 \mathrm{~cm}$, kelas II $130 \mathrm{~cm}$ dan kelas III $124 \mathrm{~cm}$. berdasarkan persyaratan ketentuan tersebut maka klas bibit sapi Bali jantan di Kabupaten Lombok Barat hasil penelitian ini adalah 100\% kelas I, demikian juga sapi bibit betina $100 \%$ kelas I.

Hasil penelitian demensi tubuh sapi Bali bibit di kabupaten Lombok barat baik bibit jantan maupun bibit betina sebagian besar termasuk kelompok kelas I hanya sebagian kecil yang yang tergolong kelas III. Hal ini mengindikasikan adanya peningkatan mutu genetik sapi Bali yang dicerminkan ukuran tubuh khususnya tinggi gumba di Kabupaten Lombok Barat. Capaian ini tidaklah mengherankan karena gencarnya upaya dinas terkait dalam penggunaan pejantan unggul sebagai pemacek baik melalui pekawinan alam atau pekawinan buatan (Inseminasi Buatan).

\section{Perfoman Reproduksi}

Tingkat perkembangan populasi ternak sangat tergantung pada kemampuan ternak tersebut dalam bereproduksi, semakin tinggi kemampuan ternak dalam bereproduksi, maka semakin tinggi pula pertumbuhan populasi ternak tersebut setiap tahunnya. Potensi reproduksi ternak dapat dilihat dari dari sifat-sifat reproduksinya antara lain, jumlah perkawinan per kebuntingan (service per conception), lama waktu ternak dalam keadaan 
tidak bunting (days open) dan angka kelahiran. Hal-hal inilah yang sangat menetukan tinggi rendahnya tingkat efisiensi reproduksi ternak. Hasil pengamatan reproduksi sapi di daerah lokasi penelitian dapat dilihat pada Tabel 4.

Tabel 4. Performan Reproduksi sapi Bali di Kabupaten Lombok Barat

\begin{tabular}{cll}
\hline No & \multicolumn{1}{c}{ Peubah } & \multicolumn{1}{c}{ Capaian } \\
\hline 1 & Angka kelahiran (\%) dari: & 78.57 \\
& a. Jumlah Induk & 27.39 \\
& b. Populasi & $0.48: 0.52$ \\
2 & Ratio kelahiran jantan dan betina & 2.49 \\
3 & Angka Kematian (\%) dari populasi & \\
4 & Natural Increase (\%) dari : & 76.08 \\
& a. Jumlah induk & 24.90 \\
& b. Populasi & $31.48 \pm 10.49$ \\
5 & An Estrus Pos Partum (hari) & $58.64 \pm 16.93$ \\
6 & Kawin Kembali sehabis beranak (hari) & $1.16 \pm 0.37$ \\
7 & Service Per Consetion & \\
8 & Lama Penggunaan dalam Pembiyakan (tahun) & 5 \\
& a. Jantan & 8 \\
& b. Betina & $2.05 \pm 0.13$ \\
9 & Umur Pubertas (tahun) a. Jantan $\quad$ b. betina & $1.50 \pm 0.24$ \\
& $\quad$ Calving Interval (bulan) & $11.08 \pm 1.10$ \\
11 & Tingkat Produktivitas (\%) & 24,28 \\
\hline
\end{tabular}

Hasil survey terhadap kinerja reproduksi sapi Bali yang dimiliki responden (Tabel 4) terlihat bahwa angka kelahiran sebesar $78.58 \%$ dari populasi betina dewasa yang ada dikelompok tersebut atau $27.39 \%$ dari populasi dasar. Angka kematian sapi Bali sebesar $2.49 \%$ dari populasi sehingga pertumubuhan alami (natural increase) yang dicapai sebesar $24.90 \%$ dari populasi. Hasil penelitian ini masih bisa ditingkatkan mengingat sapi Bali mempunyai kinerja reroduksi yang tinggi.

Pendapatan usaha pembibitan sangat tergantung pada efisiensi reproduksi ternak yang diusahakan. Apabila ternak yang dipelihara mampu menghasilkan anak setiap tahun, maka peternak akan mendapatkan nilai ekonomi yang lebih tinggi bila dibandingkan dengan peternak yang memelihara ternak dengan selang beranak yang lebih dari satu tahun, makin tinggi daya reproduksi ternak maka makin tinggi pula produktivitas ternak tersebut.

Tabel 4 memperlihatkan bahwa induk sapi Bali estrus pertama setelah beranak rata-rata $31.48 \pm 10.49$ hari, walaupun demikian peternak tidak langsung mengawinkan ternaknya tetapi menunggu sampai estrus ke dua atau ke tiga karena inseminator tidak mau melayani peternak dengan alasan angka konsepsinya rendah. Hal ini disebabkan karena involusi uterus belum sempurna, Ihsan (1992) menyatakan bahwa involusi uterus pada sapi dicapai 35 - 45 hari pasca beranak. Putro (2009) menyatakan, \pm 42 hari setelah beranak sapi sudah mulai timbul gejala berahi pertama, tapi data yang ada menunjukkan bahwa sapi yang di IB pada berahi pertama setelah beranak biasanya angka konsepsinya masih rendah. Oleh karena itu sapi dikawinkan setelah beranak pada periode berahi berikutnya \pm 63 hari setelah beranak. 
Kawin kembali sehabis melahirkan pada sapi Bali di Kabupaten Lombok Barat adalah $58.64 \pm 16.93$ hari. Untuk mendapatkan satu ekor setiap tahun dari seekor induk, maka induk sapi harus dikawinkan secepat mungkin pasca melahirkan. Apabila sapi bisa tepat waktu untuk dikawinkan setelah melahirkan maka tidak mustahil bisa menghasilkan anak setiap tahun.Jaenuddin dan Hafez (2000) menyatakan bahwa jika menginginkan satu induk menghasilkan anak satu setiap tahun, sapi harus dikawinkan 55-85 hari setelah beranak.

Hasil penelitian jumlah kali servis hingga terjadi kebuntingan pada sapi Bali berkisar antara 1-2 kali dengan rata-rata $1.16 \pm 0.37$ kali. Hal ini membuktikan bahwa tingkat kesuburan sapi Bali di Kabupaten Lombok Barat tergolong cukup tinggi. Partodihardjo (1990) menyatakan nilai angka per kawinan yang baik 1.5-1.7. Makin rendah nilai service per conception suatu peternakan maka semakin tinggi tingkat fertilitasnya, sebaliknya semakin tinggi nilai service per conceptionakan semakin rendah tingkat fertilitasnya. Nilai $\mathrm{S} / \mathrm{C}$ yang normal berkisar antara 1.6 sampai 2.0, makin rendah nilai S/C makin tinggi nilai kesuburan ternak betina (Toelihere, 1993). Selang beranak hasil penelitian ini cukup pendek yaitu 11,08 $\pm 1,10$ bulan dibanding dengan yang dilaporkan Talib et al 2002, sapi Bali di Nusa Tenggara Barat pubertas pertama terjadi pada umur 2.5 tahun, jarak antar beranak 16 bulan dan angka kematian 15\%. Pendeknya selang beranak pada penelitian ini disebabkan keberhasilan peternak dalam memenej pekawinan ternak, terutama mempependek selang antara kelahiran dengan kawin kembali sehabis beranak yakni 58.64 \pm 16.93 hari.

4. Kapasitas Suplay Sapi Bibit dan Potong

Kapasitas produksi sapi Bali dapat diukur dari jumlah ternak yang dapat dihasilkan oleh kelompok ternak tersebut setiap tahun yang bisa dicerminkan dari besarnya capain angka pertumbuhan alami serta tingkat perkembangan dan struktur populasi dasar kelompok ternak tersebut. Berdasarkan koefesien teknis (Tabel 2) dan data populasi sapi Bali tahun 2019 (119.186 ekor) dapat di lakukan enstimasi struktur populasi ternak sapi Bali tahun 2019 seperti tertera pada Tabel berikut.

Tabel 5. Estimasi Kemampuan Penyediaan sapi Bali Bibit dan potong di Kabupaten Lombok Barat

\begin{tabular}{ccccccc}
\hline \multirow{2}{*}{ Umur } & \multicolumn{3}{c}{ Jenis Kelamin } & \multicolumn{2}{c}{ Total } \\
& Ekor & $\%$ & Ekor & $\%$ & Ekor & $\%$ \\
\hline Anak sapihan & 19262 & 16.17 & 20466 & 17.17 & 39729 & 33.33 \\
Muda & 7825 & 6.57 & 17457 & 14.65 & 25279 & 21.22 \\
Dewasa & 6621 & 5.56 & 47554 & 39.90 & 54170 & 45.45 \\
Total & 19262 & 28.28 & 85477 & 71.72 & 119186 & 100 \\
\hline
\end{tabular}

Keterangan : Diolah dari Data Dinas Peternakan Kabupaten Lombok Barat (2019) dan Data Primer Hasil Penelitian (2020)

Tabel 5 memperlihatkan tingkat produksi calon bibit sapi Bali di daerah kabupaten lombok barat sebesar 39729 ekor yang terdiri dari sapi Bali jantan sebanyak 19262 ekor dan sapi Bali betina sebanyak 20466 ekor. Nilai ini setara dengan kapasitas suplai (stock) bibit. 
Jumlah sapi Bali sebagai calon pengganti sebanyak 25279 ekor yang terdiri dari 7825 ekor jantan sebagai stok ternak bakalan dan 17457 ekor betina sebagai stok ternak bibit. Jumlah sapi Bali yang diafkir (Culling) sebanyak 7770 ekor ( $6.52 \%$ dari populasi) yang terdiri dari jantan afkir 2574 ekor (2.16\%) dan betina afkir sebanyak 5196 ekor (4.36\%), sebagai stock ternak potong nilai ini juga merupakan nilai kebutuhan calon betina dan pejantan pengganti.

Berdasarkan hasil perhitungan diketahui, kapasitas suplai bibit dan ternak potong di kabupaten Lombok Barat sebesar 24.28\% dari populasi dasar, jumlah ternak sapi Bali yang dapat dikeluarkan sebagi ternak bibit dan bakalan sebanyak 21167 ekor $(17.76 \%$ dari populasi), terdiri 9713 ekor bibit (8.15\%) dan 11453 ekor sapi bakalan (9.61\%) per tahun. Sedangkan jumlah ternak sapi Bali yang dapat dikeluarkan sebagai ternak potong setiap tahun sebanyak 7770 ekor (6.52\% dari populasi), berasal dari ternak afkir jantan dan betina.

\section{KESIMPULAN}

Capaian bobot badan sapi Bali di kabupaten lombok barat pada umur fisiologi anak lepas sapih, muda dan dewasa bertutrut-turut ; 129.65, 247.98 dan $275.75 \mathrm{~kg}$ dengan ukuran tinggi gumba 99.08, 112.75 dan $118.45 \mathrm{~cm}$, Kapasitas suplai ternak bibit dan bakalan sapi Bali di Kabupaten Lombok Barat sebanyak 21167 ekor per tahun (17.76\% dari populasi), dan jumlah ternak sapi yang dapat dihasilkan sebagai ternak potong setiap tahun sebanyak 7770 ekor (6.25\% dari Populasi), Struktur populasi sapi Bali di Kabupaten Lombok Barat terdiri atas anak, muda, dan dewasa berturut-turut 33.33, 21.21 dan 45.45\%, dan angka panen anak (calf crop) mencapai $26.97 \%$ dari populasi dan angka pertumbuhan alami (Natural increase) $24.90 \%$ dari populasi.

\section{Ucapan Terima Kasih}

Terima kasih kami sampaikan kepada bapak Rekor Unversitas atas bantuan dana yang diberikan sehingga penelitian ini dapat kami laksanakan.

\section{DAFTAR PUSTAKA}

Anonim, 2017. Badan Standardisasi Nasional Bibit sapi Potong -bagian 4: Bali. Ditjen pkh Petanian. Jakarta. http://bibit.ditjenpkh.pertanian. Diakses tanggal 25 April 2020.

Arman, C, I. P., Sudrana, M. Ashari, I. B. Dania, H. Poerwoto, 2007. Profil Produksi, Reproduksi dan Produktivitas Ternak sapi Bali di Nusa Tenggara Barat. Fakultas Peternakan Universitas Mataram.

Dania I.B.H. Poerwoto, R. Andriati, M. Ashari dan Rr. A. Suhardiani, 2013. Bahan Ajar Manajemen Ternak Potong dan Kerja. Laboratorium Ternak Potong dan Kerja. Fakultas Peternakan Univrsitas Mataram. Mataram.

Dwipa, I. B. G., B. J. Sarwono, H. Poerwoto, T. Hijaz dan M. Wahyudi, 1989. Sifat Produksi Sapi Hasil Kawin Suntik di Kabupaten Lombok Barat. Laporan Penelitian. Fapet Unram. Mataram.

Hafez, E. S. E., 2000. Reproduction in Farm Animal 7th ed. Lea febiger.Philadelpia. 
Harjosubroto, W., 1994. Aplikasi Pemuliabiakan Ternak di Lapangan. PT. Gramedia Widiasmara Indonesia. Jakarta.

Ihsan, M. N., 1992. Diktat Inseminasi Buatan.Program Studi Reproduksi dan Pemuliaan Ternak.Animal Husbandry Project.UB. Malang.

Muladno, 2012. Seputar Teknologi Rekayasa Genetika. Pustaka Wira Usaha Muda. Bogor Baru.

Pane, I. 1993. Upaya Pennkatan Mutu Genetik Sapi Bali di P3 Bali. Seminar Nasional Sapi Bali. Fakltas Peternakan Universitas Udayana. Denpasar. Bali.

Partodihardjo, 1990. Ilmu Reproduksi Hewan. Mutiara. Jakarta.

Putro, P.P., 2009. Reproduksi, Pengembangan dan Kesehatan Ternak Sapi Brahman atau Peranakan Ongole (PO). Bagian Reproduksi dan Kebidanan. Fakultas Kedokteran Hewan. Universitas Gajah Mada. Yogyakarta.

Talib, C., K. Entwistle, A. Siregar, S. Budiarti-turner and D. Linsday, 2002. Survey on Population Dynamics of Bali Cattle and Exsisting Breeding Program in Indonesia.Working Paper.Bali Cattle Workshop.Bali 4-7 Februari 2002.

Tarumingkeng, R. C. 1995. Dinamika Populasi Kajian Ekologi Kuantitatif. Pustaka Sinar Harapan. PT. Midas Surya Grafindo. Jakarta.

Toelihere, M. R. 1993. Inseminasi Buatan Pada Ternak. Cetakan ke 10.Angkasa. Bandung. 